\title{
Observed impacts of the COVID-19 pandemic on global trade
}

\author{
Jasper Verschuur ${ }^{1 凶}{ }^{凶}$ Elco E. Koks ${ }^{1,2}$ and Jim W. Hall ${ }^{1}$
}

ARISING FROM D. Guan et al. Nature Human Behaviour https://doi.org/10.1038/s41562-020-0896-8 (2020)

Guan and colleagues ${ }^{1}$ used a model of the global economy to quantify the impacts of the coronavirus disease 2019 (COVID-19) pandemic under different scenarios of pandemic spreading and lockdown stringencies. Using real-time ship tracking data from before and during the pandemic, we show how the onset of disruption to trade was slower than modelled by Guan et al. Whereas supply chains to some countries with strong trading links to China (for example, Australia and Malaysia) have been affected in ways that resemble the results of their model (although to a lower extent than predicted), others with equally strong links (for example, Vietnam) have managed to increase their trade, contrary to the model's predictions. Understanding the propagation of the economic shock from COVID-19, which can be informed by real-time observations as well as model predictions, will help to better allocate international aid and economic stimuli.

Adaptive economic input-output models, as used in Guan et al. ${ }^{1}$, are one of the main classes of models used to estimate the direct and indirect economic losses from large-scale natural disasters such as floods and earthquakes ${ }^{2-4}$. To represent supply-chain linkages between countries, these models use multiregional economic input-output tables 5 . They are thus able to model the effects that the economic shock from a natural disaster will have on producers, intermediate businesses and consumers across countries and sectors. Although these models are based on increasingly sophisticated assumptions about impacts and recovery from disasters ${ }^{3,4}$, they are inevitably difficult to validate because disasters are rare and relevant information on impacts is difficult to obtain ${ }^{6}$. We argue that the type of economic model used by Guan et al. needs more rigorous validation before being applied to a rather different context (a pandemic with worldwide impacts) to the one for which it was built (localized natural disasters).

We used real-time shipping data, using Automatic Identification System (AIS) signals of vessels (see Supplementary Methods), as a complementary data source and reflect on the similarities and differences between these observations and the modelled dynamics in Guan et al. Maritime trade accounts for approximately $80 \%$ of international trade in terms of volume ${ }^{7}$, serving as an indicator of the status of the global supply-chain disruptions. We analysed the entire AIS database from the outset of the pandemic (January to June 2020) to track the quantities of goods moved by vessels ${ }^{8}$ and estimate maritime trade flows at ports globally with an algorithm that we developed and validated (Supplementary Results and Supplementary Figs 1 and 2). We compared these data with equivalent data from before the pandemic (November to December 2019). It should be noted that the methodologies are not directly comparable, as maritime trade flows are only one component of the economic system and input-output models are not designed to represent sub-annual dynamics. However, with the more detailed data that we have obtained we show how the modelled and observed disruption dynamics differ due to the limited capabilities of the current state of input-output models in representing multi-country supply and demand disruption dynamics.

Figure 1a shows the impacts of the containment policies imposed in China after the first reported outbreak of the pandemic in Wuhan. The decline in exports resembles the four-month scenario in Guan et al. ${ }^{1}$ (as presented in their supplementary fig. 2), although with a less pronounced trough. As in their model, the forward propagation to Malaysia (reduced imports from China) and backward propagation to Australia (less demand for iron ore) are clearly visible in the AIS data at the moment that China reduces exports (with a time lag for Malaysia). Thus, some of the impacts of the pandemic on global trade can be effectively reproduced in the model simulations.

However, Vietnam, which was predicted to show very large losses in all of the modelled scenarios, actually increased exports after an initial small reduction around Spring Festival (Fig. 1b). This contradictory result is probably a consequence of a shift of production processes from China to Vietnam during the initial stages of the COVID-19 pandemic ${ }^{9}$, together with the less stringent and highly effective response of the Vietnamese government to contain the virus spread. Production shifts and substitution effects of this type are typically not well-represented in input-output-based impact models. Despite some of the improvements made by Guan et al. to the ARIO model ${ }^{2}$, their results indicate a clear decrease in all production outputs, underestimating the potential benefits of production shifts for some actors in the economic system.

The AIS data provides precise information about the propagation of disruption through international trade. Trade does not occur instantaneously, as transport (overland to and from ports, as well as in ships) takes time, goods may have to wait at ports and may be transhipped en route. For instance, goods imported into Western Europe from China typically take 25 to 30 days to travel port-to-port. The model used by Guan et al. ${ }^{1}$ assumes that supply constraints (for example, due to factories not operating during lockdown) propagate through supply chains instantaneously-although they do assume the existence of stocks (for example, 20 days of production) that can be used to temporarily cope with shortages. In reality, the forward propagation of shocks would be lagged with the additive effect of inventories and transit times, explaining the observed impact curves that are generally less steep and more prolonged.

The Oxford COVID-19 Government Response Tracker $(\mathrm{OxCGRT})^{10}$ reports on the stringency of COVID-19 restrictions in 160 countries around the world, showing a great deal of

'Environmental Change Institute, University of Oxford, Oxford, UK. ${ }^{2}$ Institute for Environmental Studies, Vrije Universiteit Amsterdam, Amsterdam,

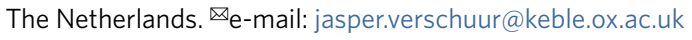




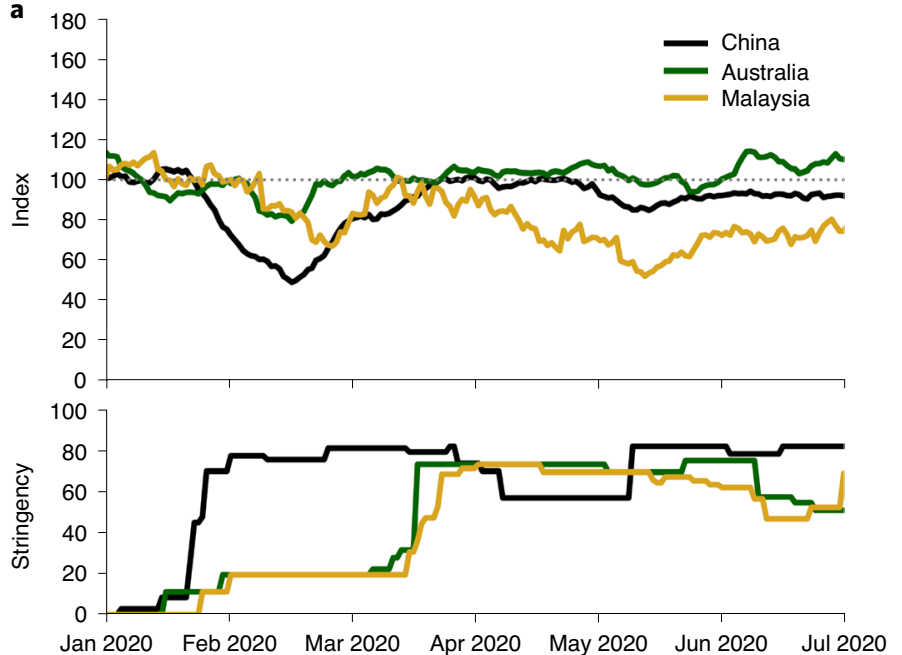

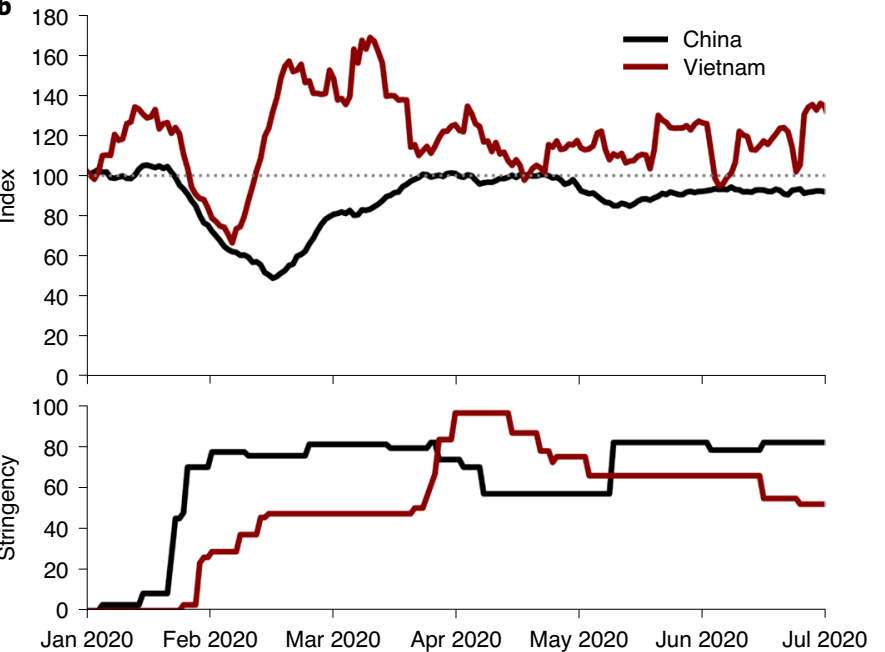

C

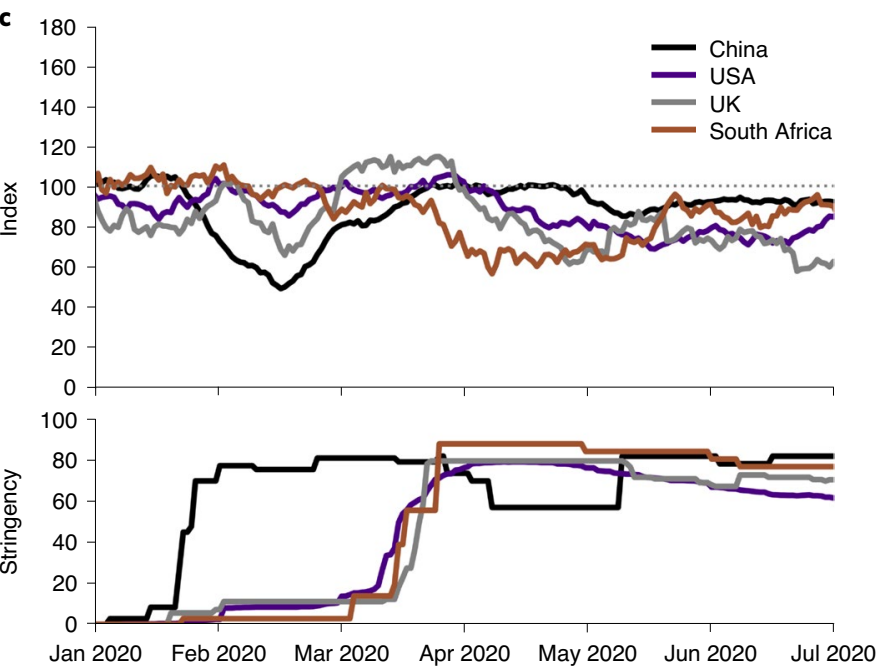

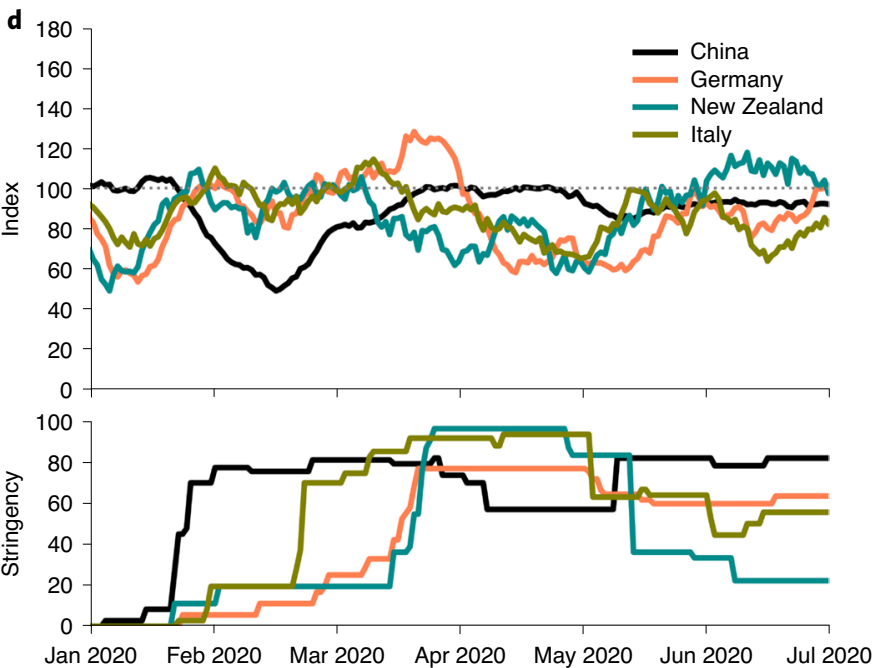

Fig. 1 | The impact of COVID-19 on shipping imports and exports from selected countries. a-d, Weighted index of imports and exports by ship (by value) based on average from November to December 2019 (100) (14-day moving averages of daily estimates). a, Shock propagation in China exports, Australia exports and Malaysia imports. b. Substitution effect in Vietnam exports during export reduction in China. c, Differences in exports for China, USA, UK and South Africa given similar lockdown stringency. d, Recovery dynamics for China, Germany, New Zealand and Italy exports after relaxing lockdown intensities.

heterogeneity between countries. Guan et al. demonstrated that the economic impacts of COVID-19 are sensitive to the speed of lockdown restrictions by testing a range of different rates of lockdown, implemented uniformly worldwide. They captured between-country heterogeneities by taking into account different sector compositions (using sector-specific multipliers). Although, admittedly, information on lockdown stringencies was not available at the time they did their analysis, our observations of trade and other work ${ }^{11}$ show that countries with similar stringency of containment measures have incurred vastly different social and economic impacts. For instance, Fig. 1c compares the export curves for China, the USA, the UK and South Africa. Exports in South Africa started to decline before the lockdown, whereas the USA shows a lagged response relative to the moment when a lockdown was imposed. Between-country differences are also apparent when comparing countries that have partially relaxed lockdowns. In Guan et al., recovery rates are relatively similar across countries. However, as shown in Fig. 1d, New Zealand experiences a much faster recovery in international trade compared with Germany and Italy, with the latter countries showing signs of a second, smaller impact on exports. Although the trade data include the effects of the lockdown, supply-chain disruptions and additional country-specific behavioural aspects (for example, lockdown enforcement and consumer confidence), which are difficult to disentangle, they do show the non-uniformity across countries. Including a sensitivity analysis of heterogeneous lockdown restrictions and the effects they have on geographical disparities of impacts would have strengthened the main conclusions of Guan et al. and helped identify which countries were likely to be hit hardest.

The modelling undertaken by Guan et al. ${ }^{1}$ provided an early indication of the scale and distribution of potential economic impacts of COVID-19 under different policy scenarios. However, using observational data of global trade from AIS ship tracking, we find both similarities and differences between the modelled dynamics and reality. Overall, the empirical evidence suggests that the modelling overestimated the negative economic impact of the pandemic. Complementary higher-frequency data sources of economic indicators, as presented here, should help to calibrate model parameters and refine and validate the modelled dynamics in cases where economic disaster models are used to evaluate scenarios of global supply-chain disruptions. Combining these methods, as is 
commonly used in nowcasting exercises, could provide policymakers with more decision-relevant information on the prioritization of post-COVID-19 recovery needs for the hardest-hit economies.

\section{Reporting Summary}

Further information on research design is available in the Nature Research Reporting Summary linked to this article.

\section{Data availability}

All derived datasets used for this analysis have been made publicly available at Zenodo under accession 4146993. The policy indicators were obtained from the Oxford Coronavirus Government Response Tracker (https://www.bsg.ox.ac.uk/research/research-projects/ coronavirus-government-response-tracker).

\section{Code availability}

Custom code that supports the findings of this study is available from the corresponding author upon request.

Received: 7 July 2020; Accepted: 21 January 2021;

Published online: 25 February 2021

\section{References}

1. Guan, D. et al. Global supply-chain effects of COVID-19 control measures. Nat. Hum. Behav. 4, 577-587 (2020).

2. Hallegatte, $\mathrm{S}$. An adaptive regional input-output model and its application to the assessment of the economic cost of Katrina. Risk Anal. 28, 779-799 (2008).

3. Koks, E. E. \& Thissen, M. A multiregional impact assessment model for disaster analysis. Econ. Syst. Res. 28, 429-449 (2016).

4. Bierkandt, R., Wenz, L., Willner, S. N. \& Levermann, A. Acclimate-a model for economic damage propagation. Part 1: basic formulation of damage transfer within a global supply network and damage conserving dynamics. Environ. Syst. Decis. 34, 507-524 (2014).

5. Lenzen, M., Kanemoto, K., Moran, D. \& Geschke, A. Mapping the structure of the world economy. Environ. Sci. Technol. 46, 8374-8381 (2012).

6. Koks, E. Moving flood risk modelling forwards. Nat. Clim. Change $\mathbf{8}$, 561-562 (2018).

7. Review of Maritime Transport 2017-Developments in International Seaborn Trade (United Nations Conference on Trade and Development, 2017).
8. Verschuur, J., Koks, E. E. \& Hall, J. W. Port disruptions due to natural disasters: insights into port and logistics resilience. Transp. Res. D. 85, 102393 (2020).

9. Google, Microsoft shift production from China faster due to virus. Nikkei Asian Review (26February2020); https://asia.nikkei.com/Spotlight/Coronavirus/GoogleMicrosoft-shift-production-from-China-faster-due-to-virus

10. Petherick, A., Hale, T., Phillips, T. \& Webster, S. Variation in government responses to COVID-19. BSG-WP-2020/032 Version 6.0 https://euagenda.eu/ upload/publications/bsg-wp-2020-032-v6.0.pdf.pdf (Blavatnik School of Government, Univ. of Oxford, 2020).

11. Hsiang, S. et al. The effect of large-scale anti-contagion policies on the COVID-19 pandemic. Nature 584, 262-267 (2020).

\section{Acknowledgements}

The authors thank the United Nations Global Working Group on Big Data for Official Statistics for providing us access to the real-time vessel tracking data. This research is supported by the University of Oxford COVID-19 Research Response Fund. J.V. acknowledges funding from the UK Engineering and Physical Sciences Research Council (EPSRC) under grant number EP/R513295/1. E.E.K. was further supported by the Netherlands Organization for Scientific Research NOW (grant no. VI.Veni.194.033). The funders had no role in study design, data collection and analysis, decision to publish or preparation of the manuscript.

\section{Author contributions}

J.V. performed the analysis of the trade flows based on shipping data, with input from E.E.K and J.W.H. All authors contributed to the discussion and writing of the article.

\section{Competing interests}

The authors declare no competing interests.

\section{Additional information}

Supplementary information The online version contains supplementary material available at https://doi.org/10.1038/s41562-021-01060-5.

Correspondence and requests for materials should be addressed to J.V.

Peer review information Nature Human Behaviour thanks the anonymous reviewers for their contribution to the peer review of this work.

Reprints and permissions information is available at www.nature.com/reprints.

Publisher's note Springer Nature remains neutral with regard to jurisdictional claims in published maps and institutional affiliations.

(C) The Author(s), under exclusive licence to Springer Nature Limited 2021 


\section{Reporting Summary}

Nature Research wishes to improve the reproducibility of the work that we publish. This form provides structure for consistency and transparency in reporting. For further information on Nature Research policies, see our Editorial Policies and the Editorial Policy Checklist.

\section{Statistics}

For all statistical analyses, confirm that the following items are present in the figure legend, table legend, main text, or Methods section.

n/a Confirmed

Х $\square$ The exact sample size $(n)$ for each experimental group/condition, given as a discrete number and unit of measurement

Х $\square$ A statement on whether measurements were taken from distinct samples or whether the same sample was measured repeatedly

$\triangle$ The statistical test(s) used AND whether they are one- or two-sided

Х Only common tests should be described solely by name; describe more complex techniques in the Methods section.

Х $\square$ A description of all covariates tested

Х $\square$ A description of any assumptions or corrections, such as tests of normality and adjustment for multiple comparisons

$\triangle$ A full description of the statistical parameters including central tendency (e.g. means) or other basic estimates (e.g. regression coefficient)

$\triangle$ AND variation (e.g. standard deviation) or associated estimates of uncertainty (e.g. confidence intervals)

Xor null hypothesis testing, the test statistic (e.g. $F, t, r$ ) with confidence intervals, effect sizes, degrees of freedom and $P$ value noted

Wive $P$ values as exact values whenever suitable.

\ $\square$ For Bayesian analysis, information on the choice of priors and Markov chain Monte Carlo settings

Х $\square$ For hierarchical and complex designs, identification of the appropriate level for tests and full reporting of outcomes

Х $\square$ Estimates of effect sizes (e.g. Cohen's $d$, Pearson's $r$ ), indicating how they were calculated

Our web collection on statistics for biologists contains articles on many of the points above.

\section{Software and code}

Policy information about availability of computer code

\section{Data collection Python3 programming}

Data analysis Python3 programming

For manuscripts utilizing custom algorithms or software that are central to the research but not yet described in published literature, software must be made available to editors and reviewers. We strongly encourage code deposition in a community repository (e.g. GitHub). See the Nature Research guidelines for submitting code \& software for further information.

\section{Data}

Policy information about availability of data

All manuscripts must include a data availability statement. This statement should provide the following information, where applicable:

- Accession codes, unique identifiers, or web links for publicly available datasets

- A list of figures that have associated raw data

- A description of any restrictions on data availability

All derived datasets used for this analysis are made publicly available at Zenodo: 10.5281/zenodo.4146993. The policy indicators are obtained from the Oxford Coronavirus Government Response Tracker (https://www.bsg.ox.ac.uk/research/research-projects/coronavirus-government-response-tracker). 


\section{Field-specific reporting}

Please select the one below that is the best fit for your research. If you are not sure, read the appropriate sections before making your selection.
Life sciences
Х Behavioural \& social sciences
Ecological, evolutionary \& environmental sciences

For a reference copy of the document with all sections, see nature.com/documents/nr-reporting-summary-flat.pdf

\section{Behavioural \& social sciences study design}

All studies must disclose on these points even when the disclosure is negative.

Study description

Research sample

Sampling strategy

Data collection

Timing

Data exclusions

Non-participation

Randomization
Observations of global maritime trade using vessel tracking data and data-driven algorithm. Methods are quantitative.

We obtained empirical vessel tracking data for the world via the UN Global Platform. This data covered the whole year 2019 and 2020 Jan-Aug.

No specific sampling strategy had to be implemented.

Data was collected from an online geospatial server and further post-processing took place on a local machine.

The data was gathered throughout the year 2020 with the latest data extraction in September 2020 to complete the full dataset that we have used in this study.

Some data was excluded as we identified them as outliers or observations that do not contribute to trade. See the Supplementary Information for a detailed description of the filtering criteria and rationale.

Participation was not relevant/necessary for our study

Randomization was not relevant/necesarry for our study

\section{Reporting for specific materials, systems and methods}

We require information from authors about some types of materials, experimental systems and methods used in many studies. Here, indicate whether each material, system or method listed is relevant to your study. If you are not sure if a list item applies to your research, read the appropriate section before selecting a response.

\begin{tabular}{|c|c|}
\hline $\mathrm{n} / \mathrm{a}$ & Involved in the study \\
\hline$\bigotimes$ & $\square$ Antibodies \\
\hline$\bigotimes$ & $\square$ Eukaryotic cell lines \\
\hline$\bigotimes$ & $\square$ Palaeontology and archaeology \\
\hline 邓 & $\square$ Animals and other organisms \\
\hline$\bigotimes$ & $\square$ Human research participants \\
\hline$\bigotimes$ & $\square$ Clinical data \\
\hline$\bigotimes$ & $\square$ Dual use research of concern \\
\hline
\end{tabular}

Methods n/a Involved in the study

\ $\square$ ChIP-seq

\ $\square$ Flow cytometry

$\bigotimes \square$ MRI-based neuroimaging 